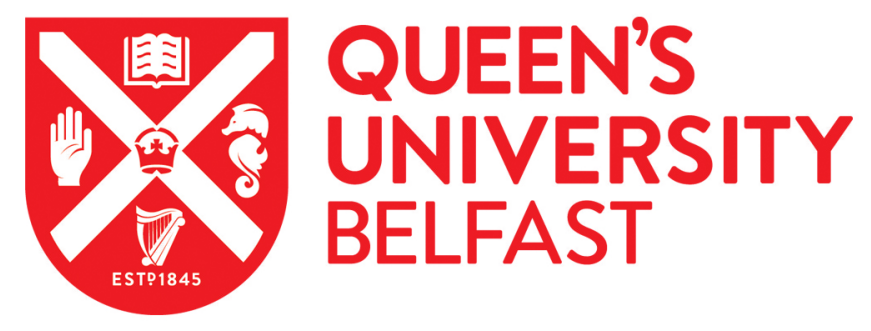

\title{
Fasting insulin concentrations and coronary heart disease incidence in France and Northern Ireland: The PRIME Study
}

Bataille, V., Perret, B., Troughton, J., Amouyel, P., Arveiler, D., Woodside, J., Dallongeville, J., Haas, B., Bingham, A., Ducimetiere, P., Ferrieres, J., \& Evans, A. (2006). Fasting insulin concentrations and coronary heart disease incidence in France and Northern Ireland: The PRIME Study. International Journal of Cardiology, 108(2), 189-196. https://doi.org/10.1016/j.ijcard.2005.04.024

Published in:

International Journal of Cardiology

Queen's University Belfast - Research Portal:

Link to publication record in Queen's University Belfast Research Portal

\section{General rights}

Copyright for the publications made accessible via the Queen's University Belfast Research Portal is retained by the author(s) and / or other copyright owners and it is a condition of accessing these publications that users recognise and abide by the legal requirements associated with these rights.

Take down policy

The Research Portal is Queen's institutional repository that provides access to Queen's research output. Every effort has been made to ensure that content in the Research Portal does not infringe any person's rights, or applicable UK laws. If you discover content in the Research Portal that you believe breaches copyright or violates any law, please contact openaccess@qub.ac.uk. 


\title{
Fasting insulin concentrations and coronary heart disease incidence in France and Northern Ireland: The PRIME study
}

\author{
Vincent Bataille ${ }^{\mathrm{a}}$, Bertrand Perret ${ }^{\mathrm{b}}$, Judith Troughton ${ }^{\mathrm{c}}$, Philippe Amouyel ${ }^{\mathrm{d}}$, Dominique Arveiler ${ }^{\mathrm{e}}$, \\ Jayne Woodside $^{\mathrm{c}}$, Jean Dallongeville ${ }^{\mathrm{d}}$, Bernadette Haas ${ }^{\mathrm{e}}$, Annie Bingham ${ }^{\mathrm{f}}$, \\ Pierre Ducimetière ${ }^{\mathrm{f}}$, Jean Ferrières ${ }^{\mathrm{a}, *}$ \\ ${ }^{\mathrm{a}}$ INSERM U 558, Department of Epidemiology, Faculty of Medicine, Toulouse, France \\ bINSERM U563, Department of Biochemistry, La Grave Hospital, CHU-Toulouse, France \\ ${ }^{\mathrm{c}}$ Department of Epidemiology and Public Health, Queen's University-Belfast, UK \\ ${ }^{\mathrm{d}}$ Pasteur Institute, Lille, France \\ ${ }^{\mathrm{e}}$ Department of Epidemiology and Public Health, Louis Pasteur University, Strasbourg, France \\ ${ }^{\mathrm{f}}$ INSERM U 258, Brousse Hospital, Villejuif, France
}

Received 8 March 2005; accepted 21 April 2005

Available online 31 May 2005

\begin{abstract}
Background: Reports about the relationships between insulin concentrations and CHD risk are controversial. The objective of this survey was to study the association between insulin levels and CHD risk in middle-aged male participants of the PRIME Study after 5 years of follow-up.

Methods: Our study adopted a nested case-control design including 294 cases of CHD and 536 controls randomly selected among healthy participants from the PRIME cohort. Data were obtained by questionnaires (medical history, lifestyle), standardised clinical measurements (blood pressure, anthropometric measurements), and a blood sample was obtained for biological measurements. Odds-Ratios for associations of four ordered classes of insulin concentration with CHD risk after adjustment for confounding factors were estimated using conditional logistic regression.

Results: In Belfast, a significant trend $(p<0.03)$ was observed between insulin classes and CHD risk in bivariate analyses, but this association lost its significance after multiple adjustments. In the French centres, a high risk of CHD (OR $=3.24$ [1.80 -5.85$], p<0.0001)$ was observed only for the second class of insulin concentration (6.5 to $9.9 \mathrm{mIU} / \mathrm{l})$, compared with the reference class $(<6.5 \mathrm{mIU} / \mathrm{l})$. After multiple adjustments, this association remained highly significant $(\mathrm{OR}=2.92$ [1.44-5.92], $p<0.005)$.

Conclusions: In Belfast (high-risk population), a significant trend was observed between insulin concentration classes and CHD risk but hyperinsulinaemia lost its association with CHD risk in multivariate analyses. In the French centres (lower risk population), slightly increased insulin concentrations were associated with a high risk of CHD, independently of cardiovascular risk factors and other features of the metabolic syndrome, but very high insulin concentrations were not.
\end{abstract}

(C) 2005 Elsevier Ireland Ltd. All rights reserved.

Keywords: CHD; Insulin; Risk; Male; Middle-aged; Prospective

\footnotetext{
* Corresponding author. INSERM U558-Faculté de Médecine, Département d'Epidémiologie 37, Allées Jules Guesde, 31073 Toulouse Cedex, France. Tel.: +335615218 70; fax: +33 562264240 .

E-mail address: jean.ferrieres@cict.fr (J. Ferrières).
}

\section{Introduction}

It is commonly acknowledged that non-insulin dependent diabetes mellitus is a major CHD risk factor [1]. However, the metabolic syndrome, a clustering of cardiovascular risk factors, particularly increased blood pressure and triglycerides [TG] and decreased high density-lip- 
oprotein cholesterol [HDL-C] along with increasing insulin concentrations, is typically observed in insulin-resistant subjects before the onset of diabetes mellitus [2]. Increased levels of prothrombotic factors, such as PlasminogenActivator-Inhibitor-1 [PAI-1] [3-6], and inflammatory markers, such as C-Reactive Protein [CRP] [6,7], have also been found to be associated with hyperinsulinaemia or more frequent in subjects with insulin resistance. Hyperinsulinaemia in the context of the metabolic syndrome is supposed to occur as a compensation for insulin resistance. However, the existence of an independent association between plasma insulin levels and coronary heart disease [CHD] risk remains controversial. Plasma insulin concentrations have been shown to be independently related to CHD risk in men in several prospective studies [8-12], but some have excluded an independent association between insulin levels and CHD risk [13-15]. A meta-analysis of data from 12 articles reporting 17 prospective studies found a weak positive association between insulin concentrations and CHD risk, with a relative risk of CHD of 1.18 (95\% CI: $1.08-1.29)$ for each $50 \mathrm{pmol} / 1(8 \mathrm{mIU} / \mathrm{l})$ increase in fasting insulin concentration [16]. In this meta-analysis, studies based on most specific insulin assays gave higher relative risks than studies based on less specific assays which also measured insulin precursors, supporting the hypothesis of an independent association of insulin with CHD risk. Conversely, recent findings from cross-sectional [17] and prospective [18-20] studies have shown that proinsulin might be a better predictor of CHD than insulin itself. The relationships between insulin concentrations and CHD risk remain unclear, and further prospective data are needed. The objective of our work was to study the association of total insulin concentrations with CHD risk in the Prospective Epidemiological Study of Myocardial Infarction [PRIME] cohort (France and Northern Ireland) after 5 years of follow-up.

\section{Population and methods}

Our study was designed as a case-control nested study within the prospective PRIME Study conducted in France and Northern Ireland in order to evaluate markers of coronary risk.

\subsection{The PRIME cohort}

The detailed protocol of the PRIME Study has already been published elsewhere [21,22]. Briefly, the PRIME cohort comprises 10592 men, aged 50-59 years, free of coronary heart disease at baseline, and recruited in the general population in France (Lille, Strasbourg and Toulouse) and in Northern Ireland (Belfast). Around 2500 subjects were recruited in each centre between April 1991 and January 1994. At baseline, after signing an informed consent, subjects had to fill in questionnaires (collecting data about socio-economic status, medical history and lifestyle), and had a medical examination including standardised measurements of height, weight, waist and hip circumferences and blood pressure. A plasma sample was also taken into tubes containing EDTA for each subject after a 12-h fast. Plasma samples were aliquoted within $15 \mathrm{~min}$ for immediate analysis (Total-cholesterol, HDL-C, TG,...) or long-term storage for ulterior planned assays (insulin). Plasma for lipids analysis was sent weekly at $4{ }^{\circ} \mathrm{C}$ to the coordinating laboratory in Lille where plasma lipids were assayed by usual methods, others aliquots were stored locally at $-80{ }^{\circ} \mathrm{C}$ and regularly sent to Lille. Data about incident cases of CHD were obtained by an annual followup performed by questionnaire. For each subject reporting a possible coronary event, details were obtained from hospitals and general practitioners and each case of CHD was validated by an independent Medical Committee. Death certificates were also used to establish details on deaths and their causes.

\subsection{The nested case-control study}

After 5 years of follow-up of the PRIME cohort, the nested case-control study was constructed as follows: for each incident CHD event which occurred during the followup, two controls were randomly selected from the participants in the PRIME cohort who remained free of CHD over the 5-year follow-up. Controls were matched for age $( \pm 3$ years), recruitment centre and examination date ( \pm 3 days). Subjects with incomplete data were excluded. If a case was excluded, his two matched controls were also excluded. If the two matched controls for a case were excluded, the corresponding case was also excluded. If one of the matched controls was excluded, both the other control and the corresponding case remained in the sample. Insulin was assayed by a competitive radioimmunoassay (Sanofi-Diagnostic Pasteur, France) in cases and their matched controls using plasma samples collected at baseline and stored in liquid nitrogen. This assay cross-reacted with precursor forms of mature insulin, including proinsulin.

\subsection{Variables}

Body mass index [BMI] was computed as weight $(\mathrm{kg})$ divided by squared height $(\mathrm{m})$, and waist-to-hip ratio [WHR] as the ratio of waist and hip circumferences. Arterial hypertension and diabetes mellitus were used dichotomised (Yes/No). Arterial hypertension was defined as blood pressure $\geq 160 / 95 \mathrm{~mm} \mathrm{Hg}$ or when the subject reported that he had had treatment for arterial hypertension. Diabetes mellitus was defined as fasting plasma glucose $\geq 7 \mathrm{mmol} / \mathrm{l}$ or when the subject reported the existence of a specific treatment for diabetes mellitus prescribed by a physician. Physical activity was studied according to three ordered classes: no physical activity or light physical activity, moderate physical activity (at least 20 min once or twice a 
week), and intense physical activity (at least 20 min more than twice a week). Self-reported alcohol consumption (number of glasses, detailed for each beverage and each day within a standard week) was used to compute the quantity of pure alcohol ingested a day [g/day]. Alcohol consumption was categorised into three classes (teetotallers, mean consumption within a standard week under $40 \mathrm{~g}$ /day and more than $40 \mathrm{~g} /$ day). Smoking habits were studied according to four classes (non-smokers, 1 to 10 cigarettes per day [cig/day], 11 to $20 \mathrm{cig} /$ day and more than $20 \mathrm{cig} /$ day).

BMI, WHR, and biochemical variables were used in their continuous form in the analyses, except for TG and CRP which were log-transformed because of skewed distributions. Insulin's distribution was also skewed and we found no adequate transformation. Insulin concentrations were so studied according to four ordered classes. The first class included subjects for whom insulin concentration was lower than the kit's first calibration point $(<6.5 \mathrm{mIU} / \mathrm{l})$. The three subsequent classes were defined according to tertiles of the control group in subjects with detectable insulin concentrations (6.5 to $9.9 \mathrm{mIU} / 1,10$ to $14.9 \mathrm{mIU} / 1$, and $\geq 15 \mathrm{mIU} /$ 1). No measurement of insulin sensitivity was available in our study. The definition of the metabolic syndrome recommended by the third report of the National Cholesterol

Table 1

Baseline characteristics of the subjects and their association with CHD risk

\begin{tabular}{|c|c|c|c|c|c|c|c|c|}
\hline & \multicolumn{4}{|c|}{ French centres } & \multicolumn{4}{|l|}{ Belfast } \\
\hline & $\begin{array}{l}\text { Cases } \\
(n=167)\end{array}$ & $\begin{array}{l}\text { Controls } \\
(n=295)\end{array}$ & OR $[95 \% \mathrm{CI}]$ & $p$ & $\begin{array}{l}\text { Cases } \\
(n=127)\end{array}$ & $\begin{array}{l}\text { Controls } \\
(n=241)\end{array}$ & OR $[95 \% \mathrm{CI}]$ & $p$ \\
\hline Tobacco consumption (\%) & & & & $0.0029 *$ & & & & $0.0017^{*}$ \\
\hline Non-smokers & 61.7 & 71.2 & - & & 58.3 & 72.2 & - & \\
\hline $1-10 \mathrm{cig} /$ day & 15.6 & 19.7 & $0.92[0.55-1.54]$ & 0.7378 & 11.0 & 10.4 & $1.04[0.48-2.23]$ & 0.9304 \\
\hline $11-20 \mathrm{cig} / \mathrm{day}$ & 15.6 & 5.4 & $3.29[1.68-6.45]$ & 0.0005 & 14.2 & 10.0 & $2.10[1.02-4.34]$ & 0.0445 \\
\hline$\geq 20 \mathrm{cig} /$ day & 7.2 & 3.7 & $2.27[0.87-5.93]$ & 0.0959 & 16.5 & 7.5 & $2.79[1.42-5.48]$ & 0.0029 \\
\hline Alcohol consumption $(\%)$ & & & & $0.0370^{*}$ & & & & $0.6217^{*}$ \\
\hline Teetotallers & 13.8 & 7.8 & - & & 42.5 & 42.3 & - & \\
\hline $1-39 \mathrm{~g} /$ day & 59.9 & 60.3 & $0.51[0.27-0.96]$ & 0.0373 & 40.2 & 38.2 & $0.99[0.60-1.63]$ & 0.9573 \\
\hline$\geq 40 \mathrm{~g} /$ day & 26.4 & 31.9 & $0.42[0.21-0.86]$ & 0.0167 & 17.3 & 19.5 & $0.84[0.44-1.58]$ & 0.5820 \\
\hline Physical activity (\%) & & & & $0.3966^{*}$ & & & & $0.4285^{*}$ \\
\hline None or light & 64.7 & 68.1 & - & & 88.2 & 90.0 & - & \\
\hline $\begin{array}{l}\text { Intense once or } \\
\text { twice a week }\end{array}$ & 26.3 & 24.1 & $1.24[0.78-1.97]$ & 0.3665 & 7.1 & 7.9 & $0.87[0.38-1.98]$ & 0.8650 \\
\hline $\begin{array}{l}\text { Intense more than } \\
\text { twice a week }\end{array}$ & 9.0 & 7.8 & $1.20[0.60-2.39]$ & 0.6088 & 4.7 & 2.1 & $2.13[0.64-7.04]$ & 0.2162 \\
\hline Body mass index $\left(\mathrm{kg} / \mathrm{m}^{2}\right)$ & $27.6[3.7]^{\mathrm{a}}$ & $26.7[3.5]$ & $1.07[1.01-1.13]$ & 0.0884 & $26.9[3.3]$ & $26.4[3.4]$ & $1.05[0.99-1.13]$ & 0.1130 \\
\hline Waist-to-hip ratio & $0.98[0.06]$ & $0.97[0.06]$ & $1.50[1.04-2.15]$ & 0.0288 & $0.96[0.06]$ & $0.94[0.05]$ & $1.70[1.15-2.54]$ & 0.0087 \\
\hline \multicolumn{9}{|l|}{ Arterial hypertension (\%) } \\
\hline No & 73.5 & 85.0 & - & & 73.2 & 80.5 & - & \\
\hline Yes & 26.5 & 15.0 & $2.42[1.40-4.20]$ & 0.0016 & 26.8 & 19.5 & $1.47[0.90-2.40]$ & 0.1266 \\
\hline \multicolumn{9}{|l|}{ Diabetes mellitus (\%) } \\
\hline No & 89.8 & 95.2 & - & & 93.7 & 97.5 & - & \\
\hline Yes & 10.2 & 4.8 & $2.35[1.05-5.23]$ & 0.0371 & 6.3 & 2.5 & $2.55[0.88-7.36]$ & 0.0846 \\
\hline $\begin{array}{l}\text { Fasting plasma glucose } \\
\qquad(\mathrm{mmol} / \mathrm{l})^{\mathrm{b}}\end{array}$ & $\begin{array}{l}1.70[0.26] \\
5.19\end{array}$ & $\begin{array}{l}1.65[0.19] \\
5.14\end{array}$ & $2.77[1.09-7.04]$ & 0.0327 & $\begin{array}{l}1.67[0.20] \\
5.11\end{array}$ & $\begin{array}{l}1.64[0.15] \\
5.04\end{array}$ & $2.55[0.75-8.68]$ & 0.1332 \\
\hline Triglycerides $(\mathrm{mmol} / \mathrm{l})^{\mathrm{b}}$ & $\begin{array}{l}0.43[0.46] \\
1.28\end{array}$ & $\begin{array}{l}0.34[0.50] \\
1.16\end{array}$ & $1.49[1.02-2.17]$ & 0.0384 & $\begin{array}{l}0.63[0.52] \\
1.67\end{array}$ & $\begin{array}{l}0.55[0.55] \\
1.45\end{array}$ & $1.37[0.90-2.08]$ & 0.1451 \\
\hline Total cholesterol (mmol/1) & $5.97[0.90]$ & $5.62[0.98]$ & $1.44[1.17-1.77]$ & 0.0005 & $6.13[1.11]$ & $5.94[1.02]$ & $1.18[0.96-1.46]$ & 0.1158 \\
\hline HDL-Cholesterol (mmol/1) & $1.18[0.37]$ & $1.28[0.34]$ & $0.92[0.86-0.97]$ & 0.0037 & $1.08[0.26]$ & $1.15[0.28]$ & $0.90[0.82-0.98]$ & 0.0143 \\
\hline C-Reactive protein $(\mathrm{ng} / \mathrm{ml})^{\mathrm{b}}$ & $\begin{array}{l}0.52[1.15] \\
1.89\end{array}$ & $\begin{array}{l}0.12[1.03] \\
1.17\end{array}$ & $1.44[1.19-1.74]$ & 0.0002 & $\begin{array}{l}0.91[1.17] \\
2.27\end{array}$ & $\begin{array}{l}0.53[1.02] \\
1.56\end{array}$ & $1.41[1.15-1.74]$ & 0.0012 \\
\hline \multicolumn{9}{|l|}{ Metabolic syndrome $(\%)^{\mathrm{c}}$} \\
\hline No & 70.6 & 77.3 & - & & 69.3 & 77.6 & - & \\
\hline Yes & 29.9 & 22.7 & $1.42[0.91-2.22]$ & 0.1193 & 30.7 & 22.4 & $1.57[0.96-2.57]$ & 0.0752 \\
\hline Insulin $(\mathrm{mIU} / \mathrm{l})(\%)$ & & & & $0.4895^{*}$ & & & & $0.0293 *$ \\
\hline$<6.5$ & 26.3 & 37.3 & - & & 18.1 & 26.6 & - & \\
\hline $6.5-9.9$ & 34.1 & 18.3 & $3.24[1.80-5.85]$ & $<0.0001$ & 21.3 & 22.8 & $1.36[0.69-2.69]$ & 0.3711 \\
\hline $10.0-14.9$ & 17.4 & 23.0 & $1.23[0.69-2.20]$ & 0.4886 & 25.2 & 22.8 & $1.63[0.86-3.11]$ & 0.1364 \\
\hline$\geq 15$ & 22.2 & 21.4 & $1.69[0.93-3.06]$ & 0.0826 & 35.4 & 27.8 & $2.00[1.05-3.83]$ & 0.0356 \\
\hline
\end{tabular}

Odds-Ratio for continuous variables are given for an increase of one unit, except for WHR and HDL-C:0.1 unit.

${ }^{\mathrm{a}}$ Mean [Standard Error].

${ }^{\mathrm{b}}$ Log-transformed (median of the original variable precised below).

c According to NCEP's definition.

* $p$ for trend. 
Education Program-Adult Treatment Panel III [NCEPATPIII][23] was used as an index of the presence or absence of a metabolic syndrome. Thus, a metabolic syndrome was considered as present if three of the five following conditions were met: Waist girth $>102 \mathrm{~mm}$, HDL$\mathrm{C}<1.03 \mathrm{mmol} / 1, \quad \mathrm{TG} \geq 1.69 \mathrm{mmol} / 1$, fasting blood glucose $\geq 6.1 \mathrm{mmol} / \mathrm{l}$ and blood pressure $\geq 130 / 85 \mathrm{~mm} \mathrm{Hg}$.

\subsection{Statistical analysis}

Statistical analyses were performed using SAS v8.2 (SAS Institute, Cary, NC, USA). Associations of classes of insulin concentrations with the characteristics of the subjects were tested using the $\chi^{2}$ test for categorical data and Student's $t$-tests for continuous data. For multivariate analyses, a conditional logistic regression model was used to assess the risk of CHD associated with concentrations at baseline of insulin or with covariates. This conditional logistic regression model enabled us to estimate OddsRatios and their 95\% confidence intervals taking the matching into account. For bivariate analyses, crude ORs and their 95\% CI were obtained by including only the variable concerned in the model.

\section{Results}

The 5-year follow-up was completed for $98.6 \%$ of the French participants and for $99.2 \%$ of the Northern-Ireland participants. During these 5 years, 335 cases of CHD (175 fatal or non-fatal myocardial infarction and 160 angina pectoris) occurred, leading to a sample composed of 1005 subjects (335 cases and 670 matched controls) for our nested case-control study. After exclusion of 175 subjects because of incomplete data, the final analyses were performed on a sample composed of 830 subjects: 294 cases and 536 controls, corresponding to 242 groups of three matched subjects ( 1 case and 2 controls), and 52 groups of two matched subjects (1 case and 1 control).

Forty two percent of the cases occurred in Belfast, 22.6\% in Toulouse, $18.8 \%$ in Strasbourg and $16.6 \%$ in Lille. Baseline characteristics of the subjects and their associations with CHD risk are summarised in Table 1. In bivariate analyses, CHD risk increased with tobacco consumption, WHR and CRP, and decreased with HDL-C in both the French centres and the Belfast centre. CHD risk was also significantly associated with arterial hypertension, diabetes mellitus, TG and total cholesterol only in the French centres. The same tendency was observed in subjects from the Belfast centre, but the differences were not statistically significant. The proportion of subjects with a metabolic syndrome as defined by the NCEP-ATPIII tended to be higher in cases than in controls, but the difference was not significant neither in Belfast nor in French centres.

When the whole sample was considered, the relationship between insulin levels and CHD risk was not linear and was different according to the recruitment centre (Fig. 1). As expected, CHD risk increased directly with total insulin concentrations in subjects recruited in Belfast ( $p$ for trend: $<0.03$ ). In this centre, the CHD risk associated with the highest class of insulin concentration was significantly increased, compared with the lowest class (OR $[95 \% \mathrm{CI}]=2.00[1.05-3.83], p<0.04)$. By contrast, in the French centres, an increased CHD risk was observed only for the second tier of insulin concentration: 6.5 to $9.9 \mathrm{mIU} / 1$, compared with the reference class $(<6.5 \mathrm{mIU} / \mathrm{l})$. This relationship was observed in each of the three French centres, and when data from these three centres were pooled, ORs [95\% CIs] were $3.24[1.80-5.85](p<0.0001)$, $1.23[0.69-2.20](p=0.49)$ and $1.69[0.93-3.06](p=0.09)$ respectively for the second, the third and the fourth tiers compared with the reference tier $(<6.5 \mathrm{mIU} / \mathrm{l})$.

Table 2 summarises the association of tiers of insulin concentration with obesity indices, plasma lipids, fasting plasma glucose, and CRP in the French and in the Belfast centres. The distributions of these parameters among tiers of insulin levels did not differ by centre. BMI, WHR, TG, fasting plasma glucose and CRP increased, and HDL-C decreased, regularly with insulin concentration. The frequencies of the metabolic syndrome, arterial hypertension and diabetes mellitus also increased directly with insulin levels both in Belfast and in the French centres. The proportions of subjects with a metabolic syndrome in the whole sample were respectively $8.3 \%, 10.9 \%, 24.5 \%$ and $58.5 \%$ across the insulin tiers $<6.5,6.5$ to $9.9,10.0$ to 14.9 and $\geq 15 \mathrm{mUI} / 1\left(\chi^{2}=181.7, p<0.0001\right)$, and this much
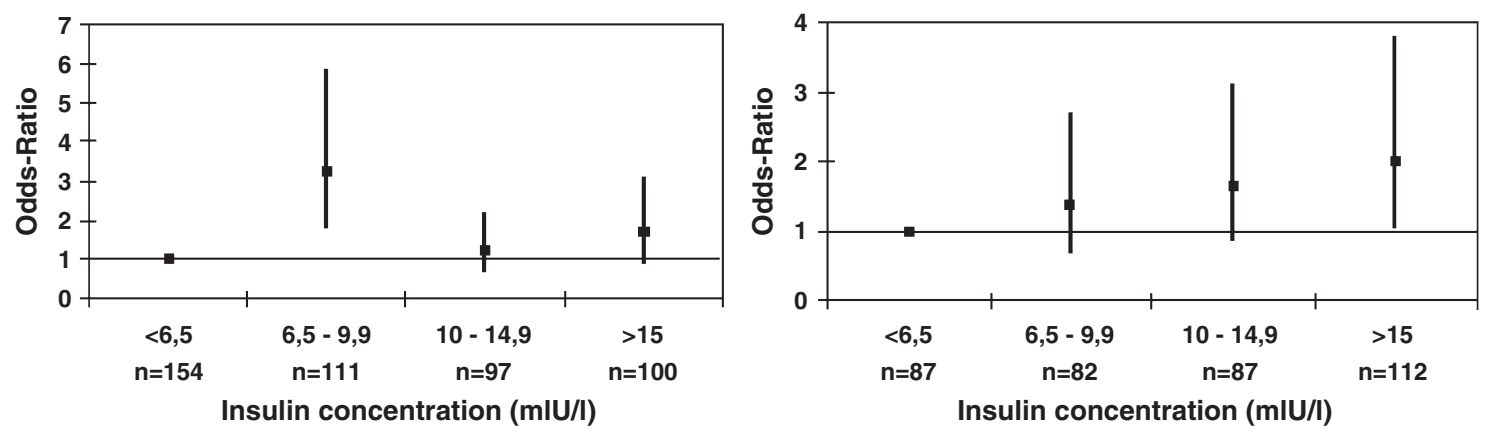

Fig. 1. Insulin and CHD risk according to recruitment centre-Crude Odds-Ratios and 95\% confidence intervals. 
Table 2

Plasma lipids, fasting plasma glucose and indexes of obesity and inflammation according to classes of insulin concentration at baseline in the whole sample

\begin{tabular}{|c|c|c|c|c|c|c|c|c|c|c|}
\hline & \multicolumn{5}{|c|}{ French centres } & \multicolumn{5}{|l|}{ Belfast } \\
\hline & \multicolumn{5}{|c|}{ Insulin concentration (mIU/l) } & \multicolumn{5}{|c|}{ Insulin concentration (mIU/l) } \\
\hline & $<6.5$ & $6.5-9.9$ & $10.0-14.9$ & $\geq 15$ & $p$ & $<6.5$ & $6.5-9.9$ & $10.0-14.9$ & $\geq 15$ & $p$ \\
\hline BMI $\left(\mathrm{kg} / \mathrm{m}^{2}\right)$ & $25.5[0.26]$ & $26.3[0.31]$ & $27.3[0.33]$ & $29.9[0.32]$ & $<0.0001$ & $24.8[0.32]$ & $25.5[0.33]$ & $26.3[0.32]$ & $29.0[0.28]$ & $<0.0001$ \\
\hline WHR & $0.94[0.01]$ & $0.97[0.01]$ & $0.98[0.01]$ & $1.01[0.01]$ & $<0.0001$ & $0.93[0.01]$ & $0.93[0.01]$ & $0.94[0.01]$ & $0.97[0.01]$ & $<0.0001$ \\
\hline $\begin{array}{l}\text { Total cholesterol } \\
(\mathrm{mmol} / \mathrm{l})\end{array}$ & $5.67[0.08]$ & $5.79[0.09]$ & $5.79[0.10]$ & $5.78[0.10]$ & 0.6593 & $5.92[0.11]$ & $5.72[0.11]$ & $6.19[0.11]$ & $6.13[0.10]$ & 0.0107 \\
\hline HDL-C (mmol/l) & $1.35[0.03]$ & $1.29[0.03]$ & $1.21[0.03]$ & $1.05[0.03]$ & $<0.0001$ & $1.28[0.03]$ & $1.12[0.03]$ & $1.11[0.03]$ & $1.02[0.02]$ & $<0.0001$ \\
\hline \multirow{2}{*}{$\begin{array}{l}\text { Triglycerides } \\
(\mathrm{mmol} / \mathrm{l})^{\mathrm{a}}\end{array}$} & $0.16[0.04]$ & $0.28[0.04]$ & $0.44[0.04]$ & $0.74[0.04]$ & $<0.0001$ & $0.25[0.05]$ & $0.37[0.05]$ & $0.68[0.05]$ & $0.91[0.04]$ & $<0.0001$ \\
\hline & 1.17 & 1.29 & 1.58 & 1.93 & & 1.19 & 1.44 & 1.90 & 2.48 & \\
\hline \multirow[t]{2}{*}{$\mathrm{FPG}(\mathrm{mmol} / \mathrm{l})^{\mathrm{a}}$} & $1.61[0.02]$ & $1.63[0.02]$ & $1.67[0.02]$ & $1.80[0.02]$ & $<0.0001$ & $1.61[0.02]$ & $1.60[0.02]$ & $1.64[0.02]$ & $1.72[0.02]$ & $<0.0001$ \\
\hline & 5.07 & 4.96 & 5.15 & 5.66 & & 4.94 & 4.90 & 5.07 & 5.36 & \\
\hline \multirow[t]{2}{*}{$\mathrm{CRP}(\mathrm{ng} / \mathrm{ml})^{\mathrm{a}}$} & $0.13[0.09]$ & $0.17[0.10]$ & $0.32[0.11]$ & $0.51[0.11]$ & 0.0348 & $0.49[0.11]$ & $0.44[0.12]$ & $0.65[0.11]$ & $0.96[0.10]$ & 0.0025 \\
\hline & 1.13 & 1.10 & 1.55 & 1.61 & & 1.38 & 1.62 & 1.70 & 2.18 & \\
\hline
\end{tabular}

${ }^{\mathrm{a}}$ Log-transformed (median of the original variable precised below).

higher proportion of subjects with a metabolic syndrome in the highest tier of insulin concentration was observed in both the Belfast and the French centres. In the same way, the proportions of diabetic subjects in the whole sample were respectively $1.2 \%, 2.1 \%, 4.9 \%$ and $13.7 \%$ across the insulin tiers $\left(\chi^{2}=40.9, p<0.0001\right)$. Thus, in the French centres, subjects in the second tier of insulin concentration did not appear to have a particularly unfavourable profile, in relation to all these factors.

In order to study the relationship between insulin concentrations and CHD risk after adjustment for confounding factors, two different models were computed: one each for the French and the Belfast centres (Table 3). For the French centres, in this conditional logistic regression model taking into account the matching for age and date of recruitment, the second class of insulin concentration ( 6.5 to $9.9 \mathrm{mIU} / \mathrm{l})$ remained significantly and independently predictive of CHD risk after 5 years of follow-up after adjustment for confounding factors and others features of the metabolic syndrome. Conversely, the CHD risk associated with the highest tier of insulin concentration $(\geq 15$ $\mathrm{mIU} / \mathrm{l})$, which was 1.69 [0.93-3.06] in bivariate analyses, was profoundly attenuated by multiple adjustments. Replacing WHR by BMI in the model did not change the results and computing this model after exclusion of subjects who

Table 3

Insulin and CHD incidence: adjusted Odds-Ratio ${ }^{\mathrm{a}}$

\begin{tabular}{llllll}
\hline & French centres & & Belfast \\
\cline { 2 - 3 } \cline { 5 - 6 } & OR $[95 \% \mathrm{CI}]$ & $p$ & & OR [95\% CI $]$ & $p$ \\
\hline Insulin (mIU/1) & & & & $0.2360^{* * *}$ \\
$0-6.4$ & - & & & \\
$6.5-9.9$ & $2.92[1.44-5.92]$ & 0.0031 & & $1.83[0.84-3.98]$ & 0.1295 \\
$10.0-14.9$ & $0.86[0.42-1.73]$ & 0.6643 & & $1.96[0.91-4.19]$ & 0.0840 \\
$\geq 15$ & $0.89[0.38-2.08]$ & 0.7935 & & $1.68[0.72-3.92]$ & 0.2265 \\
\hline
\end{tabular}

${ }^{a}$ Matched for age and date of recruitment, and adjusted for smoking habits, arterial hypertension, diabetes mellitus, WHR, total cholesterol, HDL-C, TG and CRP.

** $p$ for trend. were diabetics at baseline did not change things. Likewise, adjusting for the presence or absence of a NCEP defined metabolic syndrome instead of its components (WHR, HDL-C, TG, diabetes mellitus and arterial hypertension) did not change the results. First degree interactions were tested but none was significant. For the Belfast centre, after adjustment on the same set of covariates, insulin concentrations lost their association with CHD risk ( $p$ for trend: $0.24)$.

\section{Discussion}

After 5 years of follow-up of the PRIME Study, in a nested case-control analysis of 294 incident cases of CHD and their 536 matched controls, insulin concentrations were found to be significantly associated with CHD incidence. The relationship between insulin concentration and CHD risk was different according to the recruitment centre. In the French centres, representing a low-risk population, an increased CHD risk was observed for the second class of insulin concentration: 6.5 to $9.9 \mathrm{mIU} / \mathrm{l}$ in bivariate analyses. The CHD risk tended to be increased in the highest tier ( $\geq 15 \mathrm{mIU} / \mathrm{l}$ ), but the difference was not significant. After matching for age and adjustment for smoking habits, arterial hypertension, diabetes mellitus, WHR, total cholesterol, HDL-C, TG and CRP, a high risk of CHD remained associated with the second tier of insulin concentration $(6.5$ to $9.9 \mathrm{mIU} / \mathrm{l})$ compared with the reference tier $(<6.5 \mathrm{mIU} / \mathrm{l})$, whereas the relationship between CHD risk and the highest tier of insulin levels $(>15 \mathrm{mIU} / \mathrm{l})$ was weakened and remained non-significant. This high risk of CHD associated with slightly elevated insulin concentrations was also independent of the presence or absence of a metabolic syndrome (as defined by the NCEP-ATPIII) at baseline. In the Belfast centre, representing a high-risk population, $\mathrm{CHD}$ risk increased directly with total insulin concentration in bivariate analyses, but this association was no longer significant after multiple adjustments. 
Typical case-control studies have some limitations, and in the case of possibly fatal diseases like CHD, there is particularly a risk of a survival bias because fatal cases are inevitably absent of the sample. Prospective studies are less susceptible to these bias but require to follow and obtain measurements in a very large sample to observe enough cases. The design we adopted, a case-control study nested within the PRIME cohort including more than 10000 subjects, is a reasonable compromise.

We found a differential relationship between insulin concentrations and CHD risk in Belfast and in French centres. Differences in multicentric international studies may be attributed to differences in the way to obtain measurements. However, the questionnaires used to collect data, the methods and materials used to obtain clinical measurements or the way to ascertain cases of CHD were strictly identical in all centres participating in the PRIME study. Furthermore, all dosages were centralised in the coordinating laboratory in Lille and all frozen samples were stored in the same conditions.

In this study, insulin was measured using plasma samples which had been stored in liquid nitrogen for several years. However, a comparison of this measurement with the value of insulin concentrations obtained at baseline in a subgroup of subjects showed that long-term storage did not affect the results of insulin concentrations measurements (data not shown).

The biological assay that we used enabled the measurement of total insulin, including both mature insulin and immunologically related precursors like proinsulin. Recent findings [18-20] have shown a stronger association of CHD incidence with proinsulin than with insulin and, in experimental studies, proinsulin was found to stimulate PAI-1 expression by endothelial cells $[24,25]$. Conversely, Festa et al. [26] have shown, in a large population, that both insulin and proinsulin were associated with PAI-1, and these data did not provide evidence that the association of PAI-1 with proinsulin was stronger than its association with bioactive insulin. Furthermore, in a meta-analysis of prospective studies on insulin and CHD risk [16], Ruige et al. have shown that higher relative risks were found in studies based on more specific insulin assays than in studies based on less specific ones (cross-reacting with proinsulin like molecules). So, although the findings reported about proinsulin and CHD risk are convincing, those previous studies do support the hypothesis of the existence of an association of CHD risk with insulin itself.

Negative results have been reported from some prospective studies, stressing that no independent association exists between insulin levels and CHD risk. In a nested casecontrol study of participants in the MRFIT study [14], conducted in a large high-risk population, insulin concentrations were not associated with CHD risk. Welin et al. in Sweden [13] and Ferrara et al. in the United States [15] also found no independent association of insulin levels with CHD incidence, but these studies were conducted in older populations than ours. Haffner [27] suggested that this absence of association in elderly men could be attributable to the fact that subjects with hyperinsulinaemia might be more likely to have fatal CHD in middle ages and so might be absent in elderly populations.

The linear association of insulin concentrations with CHD risk, suggesting a high risk associated with hyperinsulinaemia, that we found in the Belfast centre in bivariate analyses is consistent with the previous findings from prospective studies in middle-aged men [8-11]. However, in PRIME, this relationship was no longer significant after adjustment for features of the metabolic syndrome. Features of the metabolic syndrome, such as increased frequency of arterial hypertension, increased WHR and TG, and decreased HDL-C, were actually more frequent in subjects with hyperinsulinaemia in our study, and this might explain the lack of association between hyperinsulinaemia and CHD risk after adjustment for these factors in subjects from Belfast. However, the estimation of the OR for this tier of insulin was not severely reduced by multiple adjustments and this negative result might also be explained by a lack of power.

Conversely, in the French centres, the estimation of the OR for this same highest insulin class was barely weakened when features of the metabolic syndrome were taken into account, suggesting that the higher CHD risk of subjects with hyperinsulinaemia may be largely explained by a higher frequency of the components of the metabolic syndrome (increased blood pressure, TG, WHR, decreased HDL-C).

The high risk of CHD we observed in subjects of the second class of insulin concentration $(6.5$ to $9.9 \mathrm{mmol} / \mathrm{l})$ in the French centres has never been described in the literature. However, a comparable relationship was observed between fasting insulin concentration and stroke incidence in the Helsinki Policemen's Study [28]. In that study, a significant trend for an association of fasting insulin concentrations with age-adjusted stroke incidence was described, but stroke incidence appeared to be slightly higher in the second quintile (almost $8 \%$ ) than in the first (less than $4 \%$ ) or the third (less than $6 \%$ ) ones. We still have no clear explanation regarding the cardiovascular risk associated with this particular insulin tier, but different explanations are possible. Insulin secretion is known to increase in insulinresistant subjects to control glycaemia, but it is also recognised that this hyperinsulinaemia can later fail to compensate for insulin resistance [29,30]. The onset of hyperglycaemia is associated with a decreasing insulin secretion by $\beta$ cells [31]. Glucotoxicity $[32,33]$ ], aggravated by lipotoxicity, related to free fatty acids as a component of the insulin resistance syndrome [33,34], on genetically predisposed $\beta$ cells are possible explanations for a decrease in insulin secretion. This hypothesis of an evolving insulin resistance, no longer compensated by an adaptative increase in insulin secretion, might be one explanation for a higher CHD risk in subjects with slightly increased insulin 
concentrations. However, this hypothesis of a decrease of insulin secretion in subjects with insulin resistance for a long time is not supported by the facts that, in our study, the frequencies of the components of the insulin resistance syndrome such as arterial hypertension, diabetes mellitus, obesity, increased TG or decreased HDLC, increased directly across the tiers of insulin concentration and that subjects of the second tier of insulin concentrations did not have a particularly adverse profile regarding these factors.

Another possible and more likely explanation for the higher risk of subjects with only slightly increased fasting insulin concentrations may be that the adaptative increased insulin secretion was not sufficient for these subjects, in the context of a beginning "sub-clinical" insulin resistance; and this surprising result might be partly attributable to the prospective design of our study: all data from questionnaires, clinical or biological measurements were only obtained at baseline and we have no data about the evolution of these parameters during the follow-up. Thus, contrary to subjects with hyperinsulinaemia at the beginning of the study, for whom insulin secretion might have been too elevated at baseline, subjects with an insulin concentration in the second tier at baseline might have been exposed during the follow-up to a relative lack of insulin in the context of a beginning "sub-clinical" insulin resistance. Unable to set up an accurate compensatory hyperinsulinaemia, these subjects might have developed an adverse risk profile earlier during the follow-up than insulin-resistant subjects for whom the compensatory hyperinsulinaemia was accurate at baseline.

In conclusion, we found an association between insulin concentrations and CHD incidence but this association differed between the French and the Belfast centres. In the high-risk population of Belfast, CHD incidence increased directly with insulin levels, but this association was no longer significant in multivariate analyses. In the French centres, subjects with insulin concentrations ranging between 6.5 and $9.9 \mathrm{mIU} / \mathrm{l}$ were at high risk of CHD, independently of confounding factors or features of the metabolic syndrome. This result may reflect that, in a low-risk population, this high CHD risk insulin concentration tier might include subjects with only slightly increased fasting insulin levels and for whom insulin secretion might be insufficient to compensate for insulin resistance.

\section{Acknowledgements}

We thank the following organisations which allowed the recruitment of the PRIME subjects: the Health screening centres organised by the Social Security of Lille (Institut Pasteur), Strasbourg, Toulouse and Tourcoing; Occupational Medicine Services of Haute-Garonne, of the Urban Community of Strasbourg; the Association Inter-entreprises des Services Médicaux du Travail de Lille et environs; the
Comité pour le Développement de la Médecine du Travail; the Mutuelle Générale des PTT du Bas-Rhin; the Laboratoire d'Analyses de l'Institut de Chimie Biologique de la Faculté de Médecine de Strasbourg; the Department of Health (NI) and the Northern Ireland Chest Heart and Stroke Association.

\section{References}

[1] Haffner SM, Lehto S, Ronnemaa T, Pyorala K, Laakso M. Mortality from coronary heart disease in subjects with type 2 diabetes and in nondiabetic subjects with and without prior myocardial infarction. N Engl J Med 1998;339:229-34.

[2] Haffner SM. Insulin resistance, inflammation, and the prediabetic state. Am J Cardiol 2003;92:18J-26J.

[3] Alessi MC, Juhan-Vague I, Kooistra T, Declerck PJ, Collen D. Insulin stimulates the synthesis of plasminogen activator inhibitor 1 by the human hepatocellular cell line Hep G2. Thromb Haemost 1988; 60:491-4.

[4] Juhan-Vague I, Thompson SG, Jespersen J. Involvement of the hemostatic system in the insulin resistance syndrome. A study of 1500 patients with angina pectoris. The ECAT Angina Pectoris Study Group. Arterioscler Thromb 1993;13:1865-73.

[5] Meigs JB, Mittleman MA, Nathan DM, et al. Hyperinsulinemia, hyperglycemia, and impaired hemostasis: the Framingham Offspring Study. JAMA 2000;283:221-8.

[6] Festa A, Hanley AJ, Tracy RP, D’Agostino Jr R, Haffner SM. Inflammation in the prediabetic state is related to increased insulin resistance rather than decreased insulin secretion. Circulation 2003; 108:1822-30

[7] Marques-Vidal P, Mazoyer E, Bongard V, et al. Prevalence of insulin resistance syndrome in southwestern France and its relationship with inflammatory and hemostatic markers. Diabetes Care 2002;25: $1371-7$.

[8] Eschwege E, Richard JL, Thibult N, et al. Coronary heart disease mortality in relation with diabetes, blood glucose and plasma insulin levels. The Paris Prospective Study, ten years later. Horm Metab Res Suppl 1985; 15:41-6.

[9] Pyorala K, Savolainen E, Kaukola S, Haapakoski J. Plasma insulin as coronary heart disease risk factor: relationship to other risk factors and predictive value during 9 1/2-year follow-up of the Helsinki Policemen study population. Acta Med Scand Suppl 1985;701:38-52.

[10] Moller LF, Jespersen J. Fasting serum insulin levels and coronary heart disease in a Danish cohort: 17-year follow-up. J Cardiovasc Risk 1995;2:235-40.

[11] Despres JP, Lamarche B, Mauriege P, et al. Hyperinsulinemia as an independent risk factor for ischemic heart disease. $\mathrm{N}$ Engl $\mathrm{J}$ Med 1996;334:952-7.

[12] Despres JP, Lemieux I, St-Pierre AC, et al. Hyperinsulinemia and ischemic heart disease risk in men: 13-year follow-up data of the Québec Cardiovascular Study. Scientific sessions of the American Heart Association. November 7-10, 2004, New Orleans, Louisiana (USA). Circulation 2004;110(17 suppl III):772.

[13] Welin L, Eriksson H, Larsson B, Ohlson LO, Svardsudd K, Tibblin G. Hyperinsulinaemia is not a major coronary risk factor in elderly men. The study of men born in 1913. Diabetologia 1992;35:766-70.

[14] Orchard TJ, Eichner J, Kuller LH, Becker DJ, McCallum LM, Grandits GA. Insulin as a predictor of coronary heart disease: interaction with apolipoprotein $\mathrm{E}$ phenotype. A report from the multiple risk factor intervention trial. Ann Epidemiol 1994;4:40-5.

[15] Ferrara A, Barrett-Connor EL, Edelstein SL. Hyperinsulinemia does not increase the risk of fatal cardiovascular disease in elderly men or women without diabetes: the Rancho Bernardo Study, 1984-1991. Am J Epidemiol 1994;140:857-69. 
[16] Ruige JB, Assendelft WJ, Dekker JM, Kostense PJ, Heine RJ, Bouter LM. Insulin and risk of cardiovascular disease: a meta-analysis. Circulation 1998;97:996-1001.

[17] Oh JY, Barrett-Connor E, Wedick NM. Sex differences in the association between proinsulin and intact insulin with coronary heart disease in nondiabetic older adults: the Rancho Bernardo Study. Circulation 2002;105:1311-6.

[18] Lindahl B, Dinesen B, Eliasson M, et al. High proinsulin concentration precedes acute myocardial infarction in a nondiabetic population. Metabolism 1999;48:1197-202.

[19] Yudkin JS, May M, Elwood P, Yarnell JW, Greenwood R, Davey Smith G. Concentrations of proinsulin like molecules predict coronary heart disease risk independently of insulin: prospective data from the Caerphilly study. Diabetologia 2002;45:327-36.

[20] Zethelius B, Byberg L, Hales CN, Lithell H, Berne C. Proinsulin is an independent predictor of coronary heart disease: report from a 27-year follow-up study. Circulation 2002;105:2153-8.

[21] Yarnell JW. The PRIME study: classical risk factors do not explain the severalfold differences in risk of coronary heart disease between France and Northern Ireland. Prospective epidemiological study of myocardial infarction. QJM 1998;91:667-76.

[22] Luc G, Bard JM, Juhan-Vague I, et al. C-reactive protein, interleukin6 , and fibrinogen as predictors of coronary heart disease: the PRIME study. Arterioscler Thromb Vasc Biol 2003;23:1255-61.

[23] Executive summary of the third report of The National Cholesterol Education Program (NCEP) expert panel on detection, evaluation, and treatment of high blood cholesterol in adults (adult treatment panel III). JAMA 2001;285:2486-97.

[24] Schneider DJ, Nordt TK, Sobel BE. Stimulation by proinsulin of expression of plasminogen activator inhibitor type-I in endothelial cells. Diabetes 1992;41:890-5.
[25] Nordt TK, Schneider DJ, Sobel BE. Augmentation of the synthesis of plasminogen activator inhibitor type-1 by precursors of insulin. A potential risk factor for vascular disease. Circulation 1994;89: $321-30$.

[26] Festa A, D'Agostino Jr R, Mykkanen L, et al. Relative contribution of insulin and its precursors to fibrinogen and PAI-1 in a large population with different states of glucose tolerance. The Insulin Resistance Atherosclerosis Study (IRAS). Arterioscler Thromb Vasc Biol 1999; 19:562-8.

[27] Haffner SM. Epidemiology of insulin resistance and its relation to coronary artery disease. Am J Cardiol 1999;84:11J-4J.

[28] Pyorala M, Miettinen H, Laakso M, Pyorala K. Hyperinsulinemia and the risk of stroke in healthy middle-aged men: the 22-year follow-up results of the Helsinki Policemen Study. Stroke 1998;29:1860-6.

[29] Kahn BB. Type 2 diabetes: when insulin secretion fails to compensate for insulin resistance. Cell 1998;92:593-6.

[30] DeFronzo RA, Bonadonna RC, Ferrannini E. Pathogenesis of NIDDM. A balanced overview. Diabetes Care 1992;15:318-68.

[31] Del Prato S, Tiengo A. The importance of first-phase insulin secretion: implications for the therapy of type 2 diabetes mellitus. Diabetes Metab Res Rev 2001;17:164-74.

[32] Rossetti L, Giaccari A, DeFronzo RA. Glucose toxicity. Diabetes Care 1990;13:610-30

[33] Grill V, Bjorklund A. Dysfunctional insulin secretion in type 2 diabetes: role of metabolic abnormalities. Cell Mol Life Sci 2000; 57:429-40

[34] Pirro M, Mauriege P, Tchernof A, et al. Plasma free fatty acid levels and the risk of ischemic heart disease in men: prospective results from the Quebec Cardiovascular Study. Atherosclerosis 2002;160: $377-84$. 